\title{
Resveratrol-Activated AMPK/SIRT1/Autophagy in Cellular Models of Parkinson's Disease
}

\author{
Yuncheng Wu ${ }^{a-c}$ Xinqun $\mathrm{Li}^{d}$ Julie Xiaohong Zhu ${ }^{b}$ Wenjie Xie ${ }^{b}$ Weidong Le ${ }^{b}$ \\ Zhen Fan ${ }^{d}$ Joseph Jankovic ${ }^{b, c}$ Tianhong Pan ${ }^{b, e}$ \\ a'Department of Neurology, Shanghai First People's Hospital, Shanghai Jiao Tong University School of Medicine, \\ Shanghai, China; 'bepartment of Neurology, Parkinson's Disease Research Laboratory, 'Department of Neurology, \\ Parkinson's Disease Center and Movement Disorder Clinic, Baylor College of Medicine, and dDepartment of \\ Experimental Therapeutics, M.D. Anderson Cancer Center, Houston, Tex., and e Diana Helis Henry Medical Research \\ Foundation, New Orleans, La., USA
}

\section{Key Words}

AMPK $\cdot$ Autophagy $\cdot$ Parkinson's disease $\cdot$ Resveratrol $\cdot$ SIRT1

\begin{abstract}
Excessive misfolded proteins and/or dysfunctional mitochondria, which may cause energy deficiency, have been implicated in the etiopathogenesis of Parkinson's disease (PD). Enhanced clearance of misfolded proteins or injured mitochondria via autophagy has been reported to have neuroprotective roles in PD models. The fact that resveratrol is a known compound with multiple beneficial effects similar to those associated with energy metabolism led us to explore whether neuroprotective effects of resveratrol are related to its role in autophagy regulation. We tested whether modulation of mammalian silent information regulator 2 (SIRT1) and/or metabolic energy sensor AMP-activated protein kinase (AMPK) are involved in autophagy induction by resveratrol, leading to neuronal survival. Our results showed that resveratrol protected against rotenone-induced apoptosis in SH-SY5Y cells and enhanced degradation of $\alpha$ synucleins in $\alpha$-synuclein-expressing PC12 cell lines via autophagy induction. We found that suppression of AMPK
\end{abstract}

and/or SIRT1 caused decrease of protein level of LC3-II, indicating that AMPK and/or SIRT1 are required in resveratrolmediated autophagy induction. Moreover, suppression of AMPK caused inhibition of SIRT1 activity and attenuated protective effects of resveratrol on rotenone-induced apoptosis, further suggesting that AMPK-SIRT1-autophagy pathway plays an important role in the neuroprotection by resveratrol on PD cellular models. Copyright $\Theta 2011$ S. Karger AG, Basel

\section{Introduction}

Parkinson's disease (PD) is the second most common neurodegenerative disease characterized by a progressive loss of dopamine (DA) neurons in the substantia nigra (SN). Although the etiology of dopaminergic neuronal degeneration remains unknown, excessive accumulation of misfolded/aggregated proteins such as mutant $\alpha$-synuclein (A53T, A30P, E46k) or accumulation of wild-type $\alpha$-synuclein with multiplications, coupled with mitochondrial dysfunction caused by neurotoxins $[1,2]$ or by mutant proteins, such as DJ-1, PINK1 and LRRK2 [3-5], have been implicated in the etiopathogenesis of PD. Im-

\section{KARGER}

Fax +4161306 1234

E-Mail karger@karger.ch

www.karger.com
(C) 2011 S. Karger AG, Basel

1424-862X/11/0193-0163\$38.00/0

Accessible online at:

www.karger.com/nsg
Dr. Tianhong Pan

Parkinson Disease Research Laboratory

Department of Neurology, Baylor College of Medicine

One Baylor Plaza, MS NB302, Houston, TX 77030 (USA)

Tel. +1 713798 5142, E-Mail tpan@bcm.edu 
paired degradation of misfolded/aggregated proteins, which may lead to neuronal death $[6,7]$, has emerged as the leading cause of neurodegeneration in PD [8].

Macroautophagy (also termed as autophagy), chaperon-mediated autophagy (CMA) and microautophagy are three major routes of autophagy-lysosomal pathway (ALP) [9], among which autophagy is inducible. Autophagy is involved in different physiological processes such as development and aging, starvation and stress, programmed cell death, and in the immune system [1013]. Down-regulation of autophagy leads to accumulation of misfolded proteins in neurons and is involved in neurodegenerative diseases such as PD $[14,15]$. Studies have indicated that approaches aimed at modulating the activities of protein degradation systems by pharmacological induction of autophagy would be promising therapeutic strategy in neurodegenerative disorders $[6$, 16-19].

Resveratrol is a nature-derived compound from red grapes, peanuts, and red wine, exhibiting a wide range of biological and pharmacological properties [20], one of which is the activation of SIRT1 [21], a mammalian ortho$\log$ of yeast silent information regulator 2 (Sir2) [22, 23]. Although resveratrol has been speculated to be a cancerchemopreventive agent $[24,25]$, recent studies have proposed that resveratrol is also an anti-inflammatory and anti-aging agent [26-29], exerting neuroprotective roles in PD models both in vitro and in vivo, including DAinduced apoptosis in neuronal SH-SY5Y cells [30], 6OHDA-treated rat model of PD [31] and MPTP-treated mice model of PD $[32,33]$. Although the activation of SIRT1 by resveratrol has been indicated to be the potential pathway towards neuroprotection [34], the possible mechanism involved is not fully understood. Recently, it has been reported that SIRT1 is sufficient to stimulate basal rates of autophagy, whereas absence of SIRT1 leads to the accumulation of damaged organelles, and disruption of energy homeostasis, indicating that SIRT1 plays important roles in the regulation of autophagy [35]. Here, we sought to investigate whether as an activator of SIRT1, resveratrol could induce autophagy that would then be yet another potential mechanism of resveratrol's neuroprotective effects.

AMP-activated protein kinase (AMPK) is a major metabolic energy sensor, which may sense energy deficiency in the form of an increased AMP/ATP ratio [36] and regulate metabolic homeostasis [37] through control of several homeostatic mechanisms, including autophagy and protein degradation [38]. The fact that resveratrol exerts multiple beneficial effects similar to those associated with energy metabolism led us to further evaluate roles of AMPK in the neuroprotection by resveratrol.

In this study, mitochondrial complex I inhibitor rotenone-treated human SH-SY5Y cells and stable inducible PC12 cell lines expressing wild-type $\alpha$-synuclein, A30P or A53T $\alpha$-synuclein mutants were used as PD cellular models for assessing the ability of resveratrol to enhance autophagy and for determining autophagy-mediated neuroprotection by resveratrol. We demonstrated that resveratrol enhanced autophagy through activation of AMPK/SIRT1 pathway and autophagy induction plays an important role in the neuroprotection of resveratrol.

\section{Materials and Methods}

\section{Cell Culture and Treatments}

SH-SY5Y cells were routinely grown in Dulbecco's modified Eagle's medium (DMEM) supplemented with $10 \%$ heat-inactivated fetal bovine serum (FBS) (Gibco, Gaithersburg, Md., USA) and cultured at $37^{\circ} \mathrm{C}$ under humidified $5 \% \mathrm{CO}_{2}$ atmosphere. Rotenone (Sigma, St. Louis, Mo., USA) stocks were dissolved in dimethyl sulfoxide (DMSO) with the stock concentration at $100 \mathrm{mM}$ and the aliquots at $20 \mu \mathrm{l}$ were frozen at $-80^{\circ} \mathrm{C}$. Resveratrol (Sigma) was prepared in DMSO at a stock of $50 \mathrm{mM}$. Other agents, including AMPK inhibitor compound $\mathrm{C}$, lysosomal function inhibitor $\mathrm{NH}_{4} \mathrm{Cl}$, and autophagy inhibitors such as bafilomycin A1 (Baf-1) and 3MA were purchased from Sigma.

Stable inducible PC12 cell lines expressing HA-tagged wildtype $\alpha$-synuclein, A30P or A53T $\alpha$-synuclein mutants (kind gifts of Prof. David Rubinsztein, Department of Medical Genetics, Cambridge Institute for Medical Research, University of Cambridge, UK) $[39,40]$ were maintained at $70 \mu \mathrm{g} / \mathrm{ml}$ hygromycin B

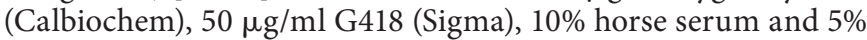
FBS DMEM and cultured at $37^{\circ} \mathrm{C}$ under humidified $5 \% \mathrm{CO}_{2}$ atmosphere. The expression of wide-type or mutant $\alpha$-synuclein was induced by $1 \mu \mathrm{g} / \mathrm{ml}$ doxycycline (Sigma) for $48 \mathrm{~h}$. Transgene expression was switched off by changing doxycycline-containing medium with fresh culture medium in the absence or presence of resveratrol.

\section{Transfection of Cells with Beclin 1 or SIRT1 siRNA}

Cells were transiently transfected with small interference RNA (siRNA) of Beclin 1 (siRNA ID: s16539; AB Applied Biosystems/Ambion) or SIRT1 (siRNA ID: s23769; AB Applied Biosystems/Ambion) using Lipofectamine ${ }^{\mathrm{TM}} 2000$ (Invitrogen). $48 \mathrm{~h}$ after transfection, cells were exposed to various treatments as specifically indicated.

\section{Cell Survival and Apoptosis Assay}

Cell death was quantified using a live/dead viability/cytotoxicity assay kit (Molecular Probes, Eugene, Oreg., USA) as we previously described [41]. Cell death detection ELISA assay kit (Roche Diagnostics) was used for the quantitative determination of cytoplasmic histone-associated DNA fragments. Apoptosis was determined by detecting the protein levels of cleaved PARP fragments using immunoblotting assay with anti-PARP antibody. 


\section{Immunoblotting Assay}

After specific treatment, total proteins were isolated with mammalian tissue lysis/extraction reagent (Sigma) and the equal amounts of protein were separated on SDS-polyacrylamide gel electrophoresis gel and transferred to a nitrocellulose membrane. After being blocked in 6\% nonfat dry milk for $45 \mathrm{~min}$, membranes were then incubated with specific primary antibodies, LC3B $(1: 5,000)$, Beclin 1 (1:1,000; Santa Cruz Biotechnology, Inc., Santa Cruz, Calif., USA), $\alpha$-synuclein (1:100; Abcam, Inc., Cambridge, Mass., USA), PARP and cleavage, caspase-3, acetyl-CoA carboxylase, acetyl-CoA carboxylase (Ser79)-p (ACC-p), acetyl-histone 3 (AC-H3), AMPK, AMPK (Thr172)-p, p62 (1:1,000; Cell Signaling). Immunoblot of $\beta$-actin (1:2,000; Santa Cruz Biotechnology, Inc.) was performed to demonstrate equal protein loading.

To determine the release of cytochrome $c$ from mitochondria, cytosolic fraction was isolated from the cell pellets according to our previous reports [42]. Briefly, cell pellets were digitonin-permeabilized for $5 \mathrm{~min}$ on ice in cytosolic extraction buffer $(250 \mathrm{mM}$ sucrose, $70 \mathrm{mM} \mathrm{KCl}, 137 \mathrm{mM} \mathrm{NaCl}, 4.3 \mathrm{mM} \mathrm{Na}_{2} \mathrm{HPO}_{4}, 1.4 \mathrm{~mm}$ $\mathrm{KH}_{2} \mathrm{PO}_{4} \mathrm{pH} 7.2,100 \mu \mathrm{M}$ PMSF, $10 \mu \mathrm{g} / \mathrm{ml}$ leupeptin, $2 \mu \mathrm{g} / \mathrm{ml}$ aprotinin, containing $200 \mu \mathrm{g} / \mathrm{ml}$ digitonin) followed by centrifugation at $1,000 \mathrm{~g}$ for $5 \mathrm{~min}$ at $4^{\circ} \mathrm{C}$. The supernatants were saved as cytosolic fractions that were subjected to immunoblot assay and visualized by probing the membranes with anti-cytochrome $c$ antibody (cyt $c, 1: 250 ;$ Abcam, Inc.). The purity of cytosol fraction was confirmed by detecting protein level of cytochrome oxidase subunit IV (COX IV), a marker of mitochondria, using immunoblotting assay with anti-mouse COX IV (Abcam, Inc.). Chemiluminescence enhancement was performed using the corresponding secondary antibody and signals were detected using Amersham ${ }^{\mathrm{TM}}$ ECL Western blotting detection reagent (GE Healthcare, UK) or with Western Lightning ${ }^{\mathrm{TM}}$ Chemiluminescence Reagent Plus (PerkinElmer LAS, Inc., Boston, Mass., USA) when necessary.

\section{Autophagy Detection}

Autophagy is an evolutionarily conserved catabolic process that is initiated by the formation of double-membrane vesicles called autophagosomes. The induction of autophagy was determined by detecting protein levels of the autophagosomal membrane form of microtubule-associated protein 1 light chain 3 (LC3) using immunoblotting assay with anti-LC3 antibody (1:5,000; kind gift of Dr. Seiji Kondo, Anthony D. Bullock III Research Laboratory in the Department of Neurosurgery at the University of Texas MD Anderson Cancer Center). To further determine the induction of autophagy, the development of acidic vesicular organelles (AVOs) was tested using the FACScan flow cytometer and CellQuest software as we have described previously [42]. Specifically, $48 \mathrm{~h}$ after resveratrol treatment, SH-SY5Y cells were incubated with acridine orange ( $1 \mu \mathrm{g} / \mathrm{ml}$; Sigma) for $15 \mathrm{~min}$. The cells were then washed with PBS and trypsinized with $1 \mathrm{ml}$ of $0.25 \%$ (w/v) trypsin-EDTA (Invitrogen). To avoid clumping of cells, cells were placed in $37^{\circ} \mathrm{C}$ for 8 min without agitating or shaking while waiting for the detachment of cells. The cells were then added with the same volume of PBS containing 10\% FBS. The resulting cell suspension at a concentration of around $1-2 \times 10^{6} / \mathrm{ml}$ was used for FACScan flow cytometer analysis. To confirm the autophagosome structures of autophagy, resveratrol-treated SH-SY5Y cells were fixed with a solution containing $3 \%$ glutaraldehyde plus $2 \%$ paraformaldehyde in $0.1 \mathrm{M}$ PBS ( $\mathrm{pH}=7.3$ ) for $1 \mathrm{~h}$ for further analysis by transmission electron microscopy analysis as we described previously [7].

AMPK/SIRT1/Autophagy and

Parkinson's Disease

\section{Statistics}

All data were collected from three or more independent experiments and the values were presented as mean \pm SD. The data were analyzed by one-way ANOVA using original software (Microcal Inc., Northampton, Mass., USA). Significant differences were defined as $\mathrm{p}<0.05$.

\section{Results}

\section{Pharmacological Induction of Autophagy by}

Resveratrol

Our results showed that resveratrol increased levels of LC3-II dose- and time-dependently (fig. 1a), indicating that resveratrol has the ability to induce autophagy. The autophagosome and autophagolysosome, collectively referred to as autophagic vacuoles (AVs), are considered as the characteristic components of autophagy. FACScan flow cytometric analysis revealed that the observed changes in LC3-II reflected the increased double membrane structures of AVs as indicated by the enhanced development of AVOs in resveratrol-treated cells (16\% of total) as compared to its vehicle control (4.5\% of total) ( $\mathrm{p}<$ 0.01 ) (fig. 1b). When autophagy-related gene Beclin 1 was suppressed by Beclin 1 siRNA transfection, the role of resveratrol in autophagy induction as indicated by the increased LC3-II was blocked accordingly (fig. 1c). LC3-II and p62 act as structural components of the autophagosomes $[43,44]$. We showed that $24 \mathrm{~h}$ after cells were treated with resveratrol, both the protein levels of LC3-II and p62 were increased (fig. 1d). When the fusion of autophagosomes to lysosome was inhibited by autophagosomelysosome fusion blocker Baf-1 [45] or when the lysosomal function was inhibited by $\mathrm{NH}_{4} \mathrm{Cl}$, the increased LC3-II and p62 were accumulated accordingly (fig. 1d), indicating that the autophagic flux was affected when autophagy-lysosomal function was inhibited. Furthermore, the results from transmission electron microscopy analysis confirmed that the structures of AVs could be observed largely in resveratrol-treated cells as compared to its vehicle control (fig. 1e).

\section{Alleviation of Rotenone-Induced Injury of SH-SY5Y Cells by Resveratrol}

Exposure of cells to rotenone caused shrinkage of $\mathrm{SH}$ SY5Y cells, which was attenuated when cells were pretreated with resveratrol (fig. 2a). Cell live/dead assay showed that exposure of cells to rotenone caused an increase in red fluorescent signal (indicating dead cells) and a decrease in green fluorescent signal (indicating live cells) (fig. 2a). Quantification analysis showed that the 


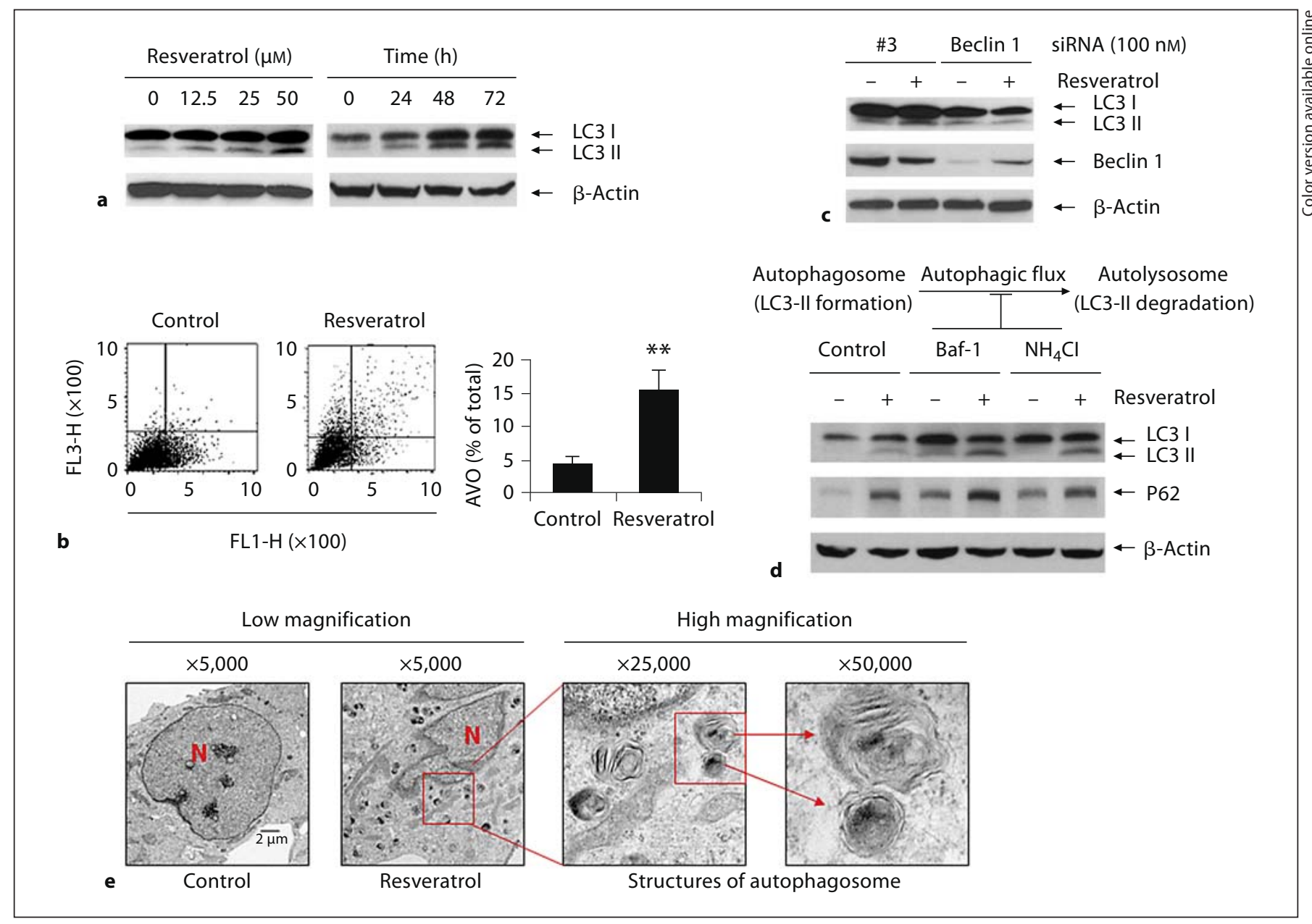

Fig. 1. Pharmacological induction of autophagy by resveratrol. a SH-SY5Y cells were treated with resveratrol at $0,12.5,25$, and $50 \mu \mathrm{M}$ for $48 \mathrm{~h}$ or at $50 \mu \mathrm{M}$ for $0,24,48$ and $72 \mathrm{~h}$. The protein levels of LC3 were determined by immunoblotting assay with antiLC3 antibody. b SH-SY5Y cells were treated with resveratrol for $48 \mathrm{~h}$ followed by staining with acridine orange $(1 \mu \mathrm{g} / \mathrm{ml})$. The induction of autophagy was determined by FACScan flow cytometric analysis. The FACScan analysis profiles were shown and the top of the grid was considered as AVOs. Development of AVO was quantified and expressed as percentage of total cells. Data were mean $\pm S D$. Mean values were from three independent experiments. ${ }^{* *} \mathrm{p}<0.01$ as compared to control. c $48 \mathrm{~h}$ after cells were transfected with Beclin 1 siRNA or its scrambled control (\#3 siRNA), cells were treated with or without resveratrol at $50 \mu \mathrm{M}$ for additional $48 \mathrm{~h}$. Cell lysates were subjected to immunoblotting

number of dead cells was significantly increased by $38 \%$ in rotenone-exposed cells as compared to control ( $\mathrm{p}<$ 0.01 ), whereas resveratrol pretreatment salvaged cells from rotenone toxicity by reduction of dead cells to $16 \%$ ( $p<0.01$; fig. 2a). ELISA assay showed that rotenone caused an increase of histone-associated DNA fragmen- assay and the protein levels of Beclin 1 and LC3 were determined with anti-Beclin 1 and anti-LC3 antibodies, respectively. $\mathbf{d}$ Cells were treated with $50 \mu \mathrm{M}$ of resveratrol for $24 \mathrm{~h} .3 \mathrm{~h}$ before harvest, cells were treated with Baf-1 (200 nM). Or, cells were pretreated with $\mathrm{NH}_{4} \mathrm{Cl}(10 \mathrm{mM})$ overnight followed by resveratrol treatment for $24 \mathrm{~h}$. Cell lysates were subjected to immunoblotting assay and the protein levels of p62 and LC3 were determined with anti-p62 and anti-LC3 antibodies. e SH-SY5Y cells were treated with resveratrol for $48 \mathrm{~h}$ followed by fixation. The double membrane structures of autophagy vacuous were analyzed by electron microscope under a JEM 1010 transmission electron microscope. The red square indicates autophagic vacuoles, including autophagosomes. The autophagosomes that contain intracellular contents are shown under high magnification $(\times 50,000) . \mathrm{N}=$ Nucleus.

tation by $70 \%$ as compared to control ( $<<0.01$; fig. $2 \mathrm{~b}$ ), which was reduced by $30 \%$ with resveratrol treatment $(\mathrm{p}<0.05$; fig. $2 \mathrm{~b}$ ). Moreover, resveratrol diminished rotenone-induced increase of cleaved PARP and caspase-3 protein levels (fig. $2 \mathrm{c}$ ), indicating the neuroprotective role of resveratrol. 


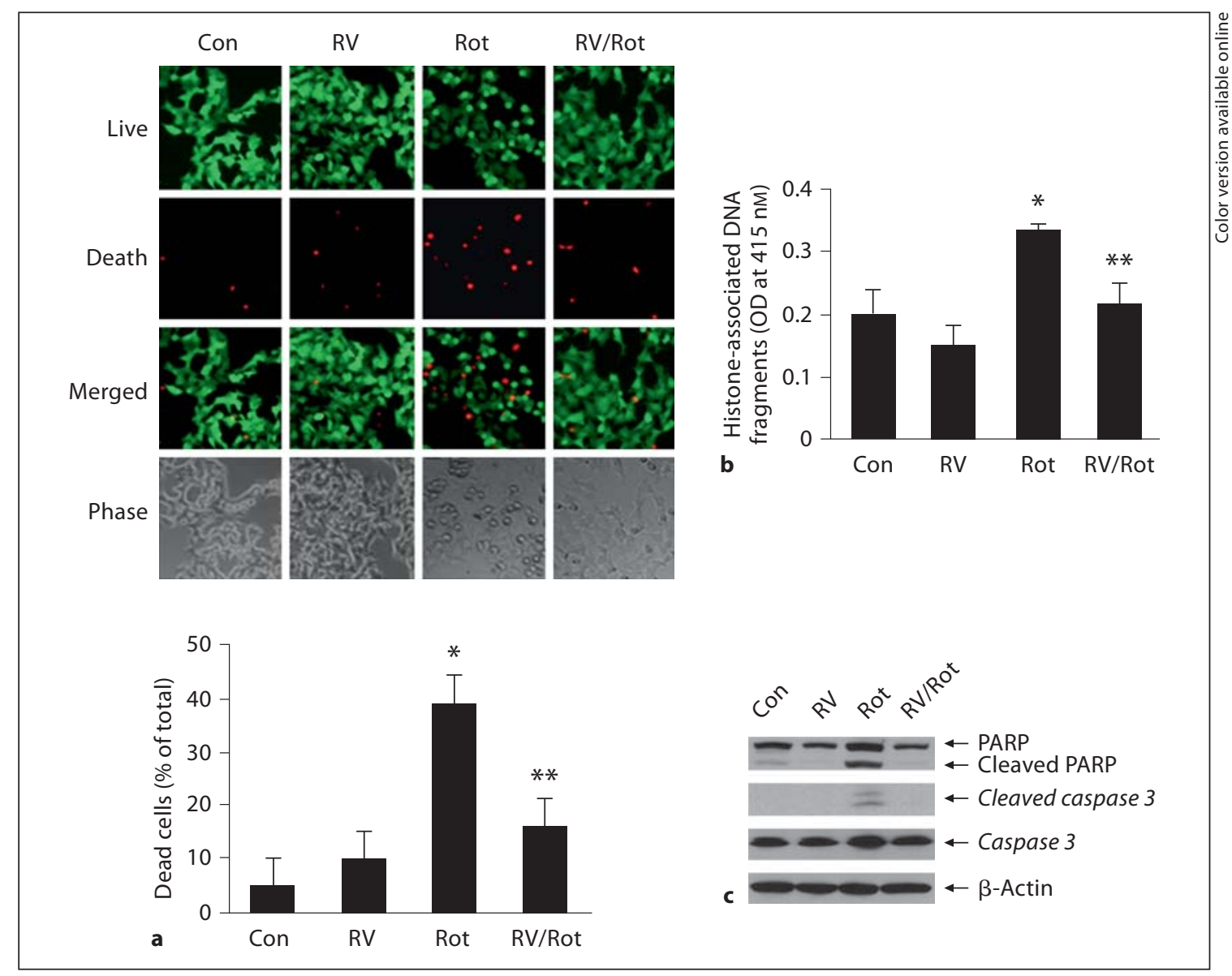

Fig. 2. Alleviation of rotenone-induced injury of SH-SY5Y cells by resveratrol. SH-SY5Y cells were exposed to rotenone $(10 \mu \mathrm{M})$ for $24 \mathrm{~h}$ with or without resveratrol $(50 \mu \mathrm{M})$ pretreatment for $24 \mathrm{~h}$. a Changes of cell morphology and cell survival and death were visualized using a live/dead assay. SH-SY5Y cells were stained with $1 \mu \mathrm{M}$ calcein AM and $1.5 \mu \mathrm{M}$ ethidium homodimer- 1 for 20 min followed by the measurement of live or dead cells using fluorescence microscope. The green fluorescence, generated by calcein AM, indicates live cells, and the red fluorescence, generated by ethidium homodimer-1, indicates dead cells. Dead cells were counted for three random microscopy sections. The number of dead cells was counted and value was expressed as percentage of total cells. Data were expressed as the means $\pm \mathrm{SD} .{ }^{*} \mathrm{p}<0.01$ as compared to Con; ${ }^{* *} \mathrm{p}<0.01$ as compared to Rot. $\mathbf{b}$ The levels of histone-associated DNA fragmentation in the cytoplasm were quantified by ELISA assay. Data were collected from three independent experiments and expressed as means \pm SD. ${ }^{*} p<0.01$ as compared to Con; ${ }^{* *} \mathrm{p}<0.05$ as compared to Rot. $\mathbf{c}$ The whole cell lysates were subjected to immunoblotting assay to determine the protein levels of cleaved PARP and caspase-3. $\beta$-Actin was used as an equal loading of proteins. Con = Control; $\mathrm{RV}=$ resveratrol; Rot $=$ rotenone .
Autophagy-Mediated Neuroprotection by Resveratrol

Our results showed that resveratrol-induced increase of LC3-II protein levels was reduced when cells were treated with autophagy inhibitor 3MA (fig. 3a). Meanwhile, resveratrol attenuated rotenone-induced apoptosis, where the effect was blocked by $3 \mathrm{MA}$ (fig. 3a), suggesting that autophagy induction is required for the neuroprotection of resveratrol. Additionally, we found that resveratrol attenuated rotenone-induced increase of cleaved PARP, which was blocked when Beclin 1 was suppressed (fig. 3b). As autophagy plays an important role in the clearance of injured mitochondria, from which apoptosis caused by released cytochrome $c$ can be prohibited, we further determined whether resveratrol could reduce cytosol protein level of cytochrome $c$ released from injured mitochondria. We found that resveratrol pretreatment diminished rotenone-induced increase of cytochrome $c$ level in cytosol fraction, which effect was blocked when Beclin 1 gene was suppressed (fig. 3c). Cox IV is one of the mitochondrial proteins. To 


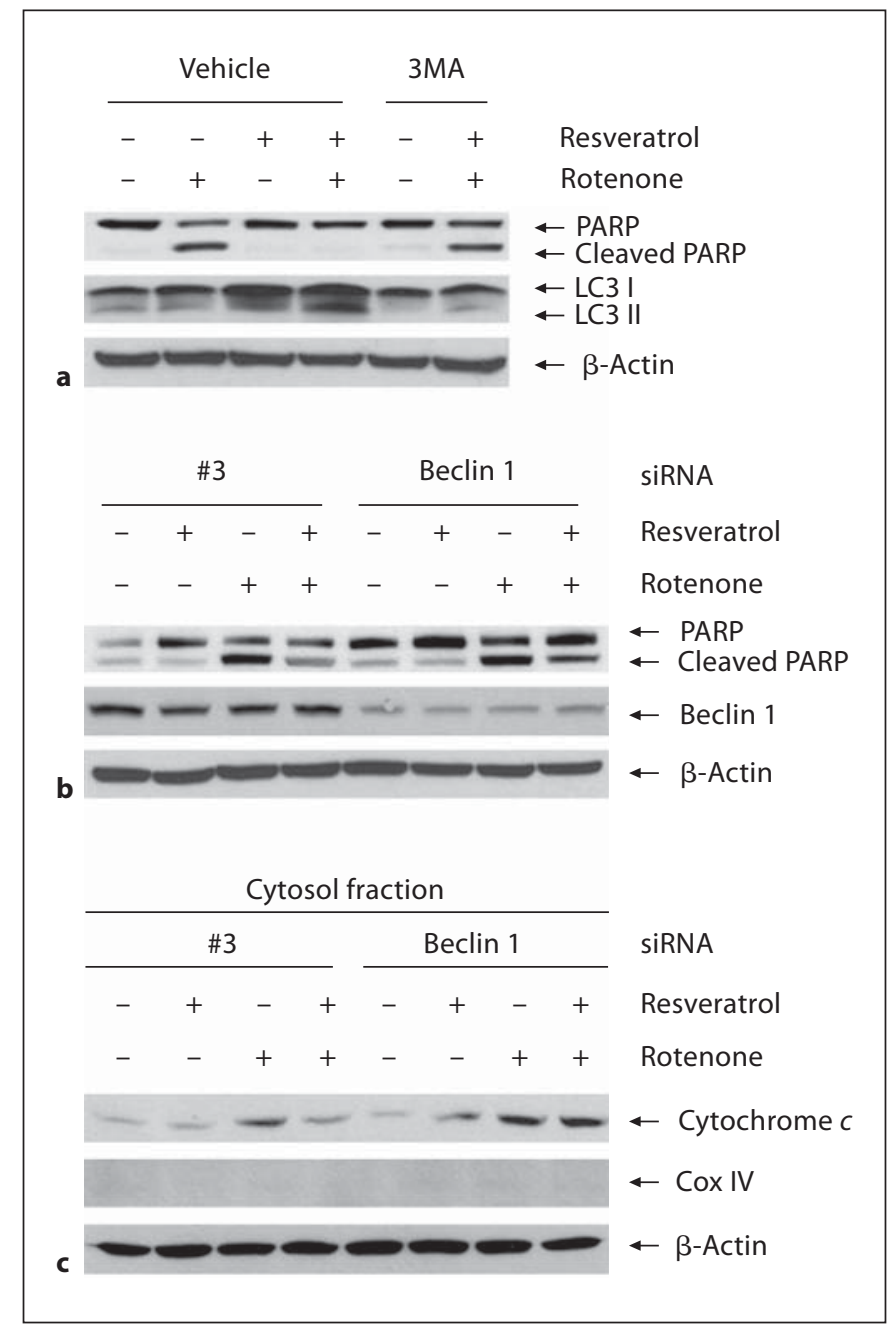

Fig. 3. Neuroprotection by resveratrol mediated through autophagy induction. a SH-SY5Y cells were pretreated with resveratrol in the absence or presence of 3MA $(10 \mathrm{mM})$ for $24 \mathrm{~h}$ followed by exposure to rotenone for another $24 \mathrm{~h}$. Apoptosis and autophagy inductions were evaluated by immunoblotting assay with antiPARP and anti-LC3 antibodies. b SH-SY5Y cells were transfected with Beclin 1 siRNA (100 nM) or negative control \#3 siRNA for $48 \mathrm{~h}$ followed by exposure to rotenone with or without resveratrol pretreatment. The whole cell lysates were subjected to immunoblotting assay and the apoptosis was evaluated using anti-PARP antibody. c The cytosol fraction was isolated and subjected to immunoblotting assay. The levels of cytochrome $c$ in cytosol fraction were determined with anti-cytochrome $c$ antibody. The purification of cytosol fraction was determined with anti-COX IV antibody.

confirm the purification of cytosol fraction, we determined protein level of Cox-IV by immunoblotting assay with anti-Cox IV antibody. The result that no Cox IV bands were detected in cytosal fraction indicated that the purification of cytosol fraction was good.
Enhanced Degradation of $\alpha$-Synucleins by Resveratrol As autophagy plays an important role in degradation of aggregated/misfolded proteins, we further tested whether resveratrol could enhance the degradation of PD causing gene $\alpha$-synuclein. We showed that doxycycline induced transgene expression of $\alpha$-synucleins in all the three cell lines (fig. 4a), which was reduced by resveratrol treatment accompanied by autophagy induction as indicated by the increased protein levels of LC3-II (fig. 4a). However, although the autophagy marker LC3-II was increased with lysosomal inhibitor $\mathrm{NH}_{4} \mathrm{Cl}$ treatment, no significant reduction of $\alpha$-synucleins protein level was observed (fig. 4a), indicating that the degradation of $\alpha$-synucleins is mediated through autophagy-lysosome pathway. Moreover, we found that the role of resveratrol in diminishing doxycycline-induced increase of $\alpha$-synucleins was blocked when Beclin 1 gene was suppressed accompanied by the inhibition of autophagy (fig. $4 \mathrm{~b}$ ).

\section{AMPK-SIRT1-Mediated Induction of Autophagy by Resveratrol}

Furthermore, we intended to explore the relationships between resveratrol and the activation of AMPK or SIRT1. As determined by immunoblotting assay using specific antibodies, we found that the phosphorylation levels of $\mathrm{Thr}^{172}$ in the active site of AMPK catalytic subunit [46] (p-AMPK) were increased with resveratrol treatment (fig. 5a). Time kinetics shows that p-AMPK reached a maximum level $24 \mathrm{~h}$ after resveratrol treatment (fig. 5b). The results that the pattern of increase of phosphorylation of ACC-Ser ${ }^{79}$ (p-ACC) was consistent to the changes of p-AMPK (fig. 5a, b) were also supported by previous reports that $\mathrm{p}$-ACC is the best-characterized phosphorylation site by AMPK [47] and p-ACC has a tight correlation with an endogenous AMPK activity [48]. However, no changes have been observed in the total amount of ACC and AMPK (fig. 5a, b). Additionally, although the protein levels of SIRT1 got only a slight increase with resveratrol treatment, the decrease of histone 3 (AC-H3), a known downstream target of SIRT1, indicated that the SIRT1 deacetylase activity was increased (fig. 5a, b).

Compound $\mathrm{C}$ is a potent AMPK inhibitor that has been widely used for studying AMPK signaling [49]. Our results showed that compound $\mathrm{C}$ prevented resveratrolinduced activation of AMPK and ACC (fig. 5c), accompanied by the decrease of LC3-II (fig. 5c), indicating that inhibition of AMPK caused autophagy inhibition accordingly. Meanwhile, although resveratrol caused no significant changes in SIRT1 protein levels, compound C 


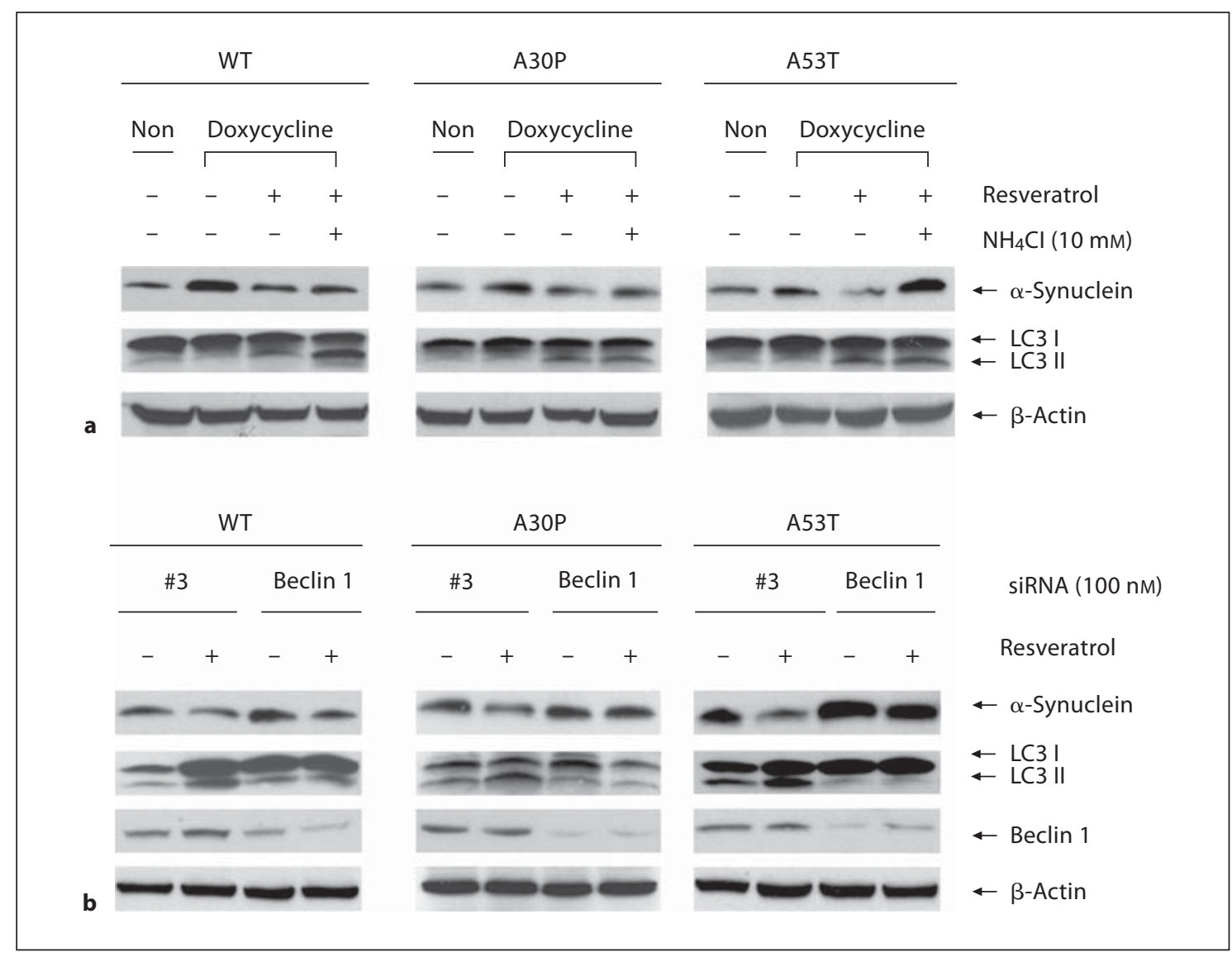

Fig. 4. Clearance of $\alpha$-synuclein by resveratrol. a Wild-type, A30P or A53T $\alpha$-synuclein transgenes were induced with doxycycline $(1 \mu \mathrm{g} / \mathrm{ml})$ in stable inducible PC12 cell lines for $48 \mathrm{~h}$ followed by resveratrol treatment with or without lysosomal inhibitor $\mathrm{NH}_{4} \mathrm{Cl}$ (10 mM) for $24 \mathrm{~h}$. b Stable inducible PC12 cell lines expressing wild-type, A30P or A53T $\alpha$-synuclein were transfected with
Beclin 1 siRNA (100 nM) or negative control \#3 siRNA. $24 \mathrm{~h}$ after transfection, cells were induced with doxycycline $(1 \mu \mathrm{g} / \mathrm{ml})$ for $36 \mathrm{~h}$. The transgene expression was switched off by replacing with fresh medium followed by treatment with resveratrol for $24 \mathrm{~h}$. Clearance of $\alpha$-synuclein was evaluated by immunoblotting assay with anti- $\alpha$-synuclein antibody. caused increase of $\mathrm{AC}-\mathrm{H} 3$, indicating that the SIRT1 deacetylase activity was decreased (fig. 5c). Furthermore, we showed that resveratrol-induced increase of LC3-II was blocked when SIRT1 gene was suppressed by SIRT1 siRNA transfection (fig. 5d), indicating that SIRT1 is required for the autophagy induction by resveratrol.

\section{Role of AMPK Activation in the Neuroprotection of Resveratrol}

As shown in figure 6a, rotenone exposure caused a time-dependent increase of cleaved PARP protein levels. The increase of $\mathrm{p}$-AMPK and $\mathrm{p}-\mathrm{ACC}$ was earlier than that of cleaved PARP, which then declined 24 or $48 \mathrm{~h}$ after rotenone incubation accompanied by a significant increase of cleaved PARP. Our results also showed that inhibition of AMPK by AMPK-specific blocker compound C enhanced susceptibility of cells to rotenone-induced apoptosis (fig. 6b) and attenuated neuroprotective effects of resveratrol on rotenone-induced apoptosis (fig. 6c).

\section{Discussion}

Autophagy is induced by various stimuli and is considered as a survival mechanism induced in adverse conditions to maintain cell integrity. Extensive studies have indicated that autophagy plays important neuroprotective roles in many neurodegenerative diseases, including PD $[7,9,42]$. Compelling evidence in the literature has shown that resveratrol is capable of inducing autophagy 
Fig. 5. Induction of autophagy by resveratrol via AMPK/SIRT1 activation. a, b SHSY5Y cells were treated with resveratrol at various concentrations for $24 \mathrm{~h}$ (a) or at 50 $\mu \mathrm{M}$ for various time durations (b). c SHSY5Y cells were pretreated with AMPK inhibitor compound $\mathrm{C}$ at $10 \mu \mathrm{M}$ for $3 \mathrm{~h}$ followed by addition of resveratrol for $24 \mathrm{~h}$. d $48 \mathrm{~h}$ after cells were transfected with SIRT1 siRNA or its scrambled control \#3 siRNA, cells were treated with or without resveratrol at $50 \mu \mathrm{M}$ for $48 \mathrm{~h}$. The whole cell lysates were subjected to immunoblotting assay and the protein levels were determined with specific antibodies indicated.

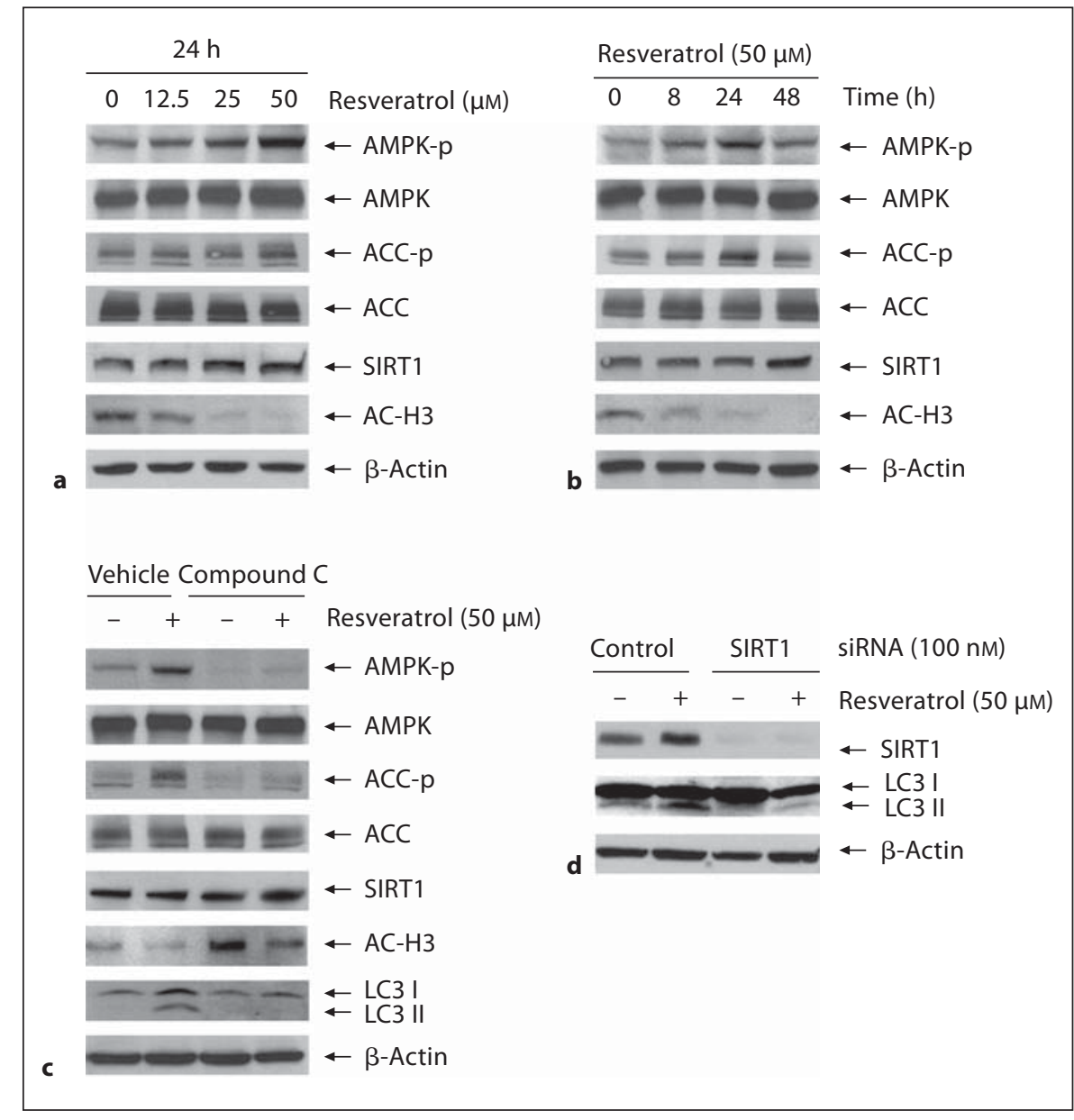

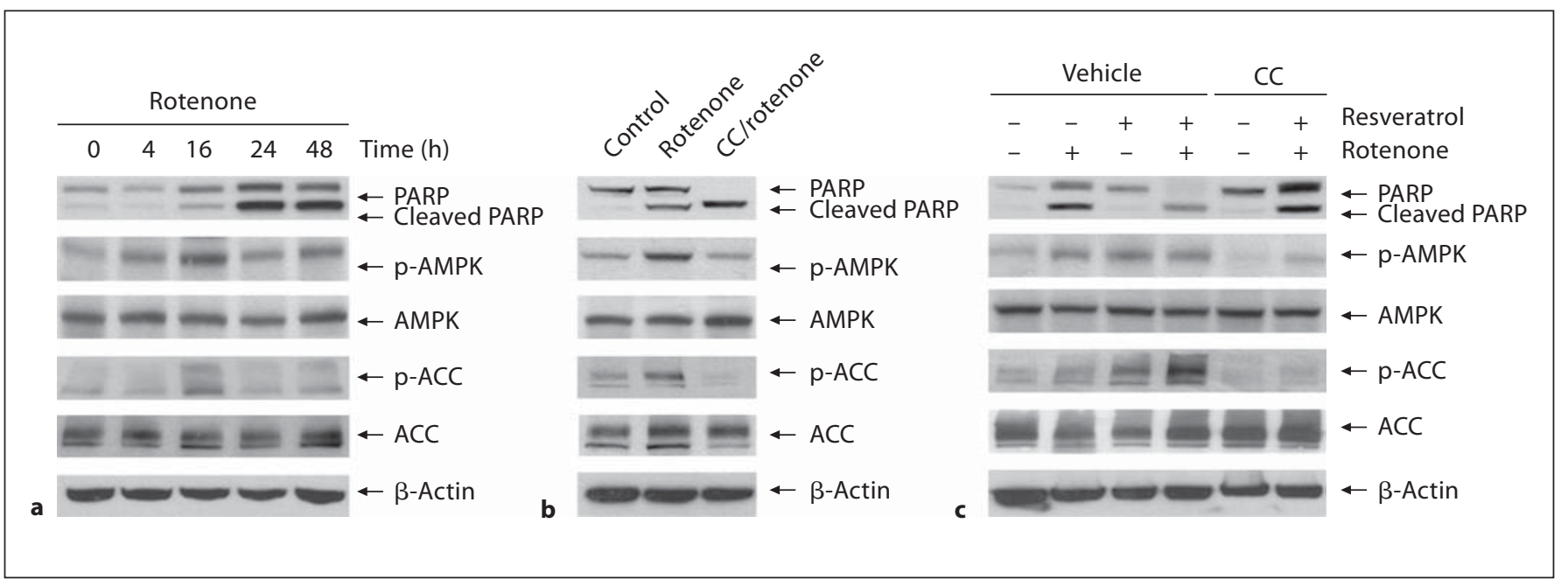

Fig. 6. AMPK activation in the neuroprotection by resveratrol. a SH-SY5Y cells were exposed to rotenone $(10 \mu \mathrm{M})$ for different time durations. b SH-SY5Y cells were treated with rotenone (10 $\mu \mathrm{M})$ in the absence or presence of compound C $(10 \mu \mathrm{M})$. c SH-SY5Y cells were pretreated with resveratrol $(50 \mu \mathrm{M})$ in the presence or absence of compound C ( $10 \mu \mathrm{M})$ for $24 \mathrm{~h}$ followed by exposure to rotenone for $16 \mathrm{~h}$. The apoptosis was evaluated by immunoblotting assay with anti-PARP antibody. The activation of AMPK was determined by measuring the protein levels of $\mathrm{p}$-AMPK and $\mathrm{p}$-ACC. $\mathrm{CC}=$ Compound $\mathrm{C}$. 


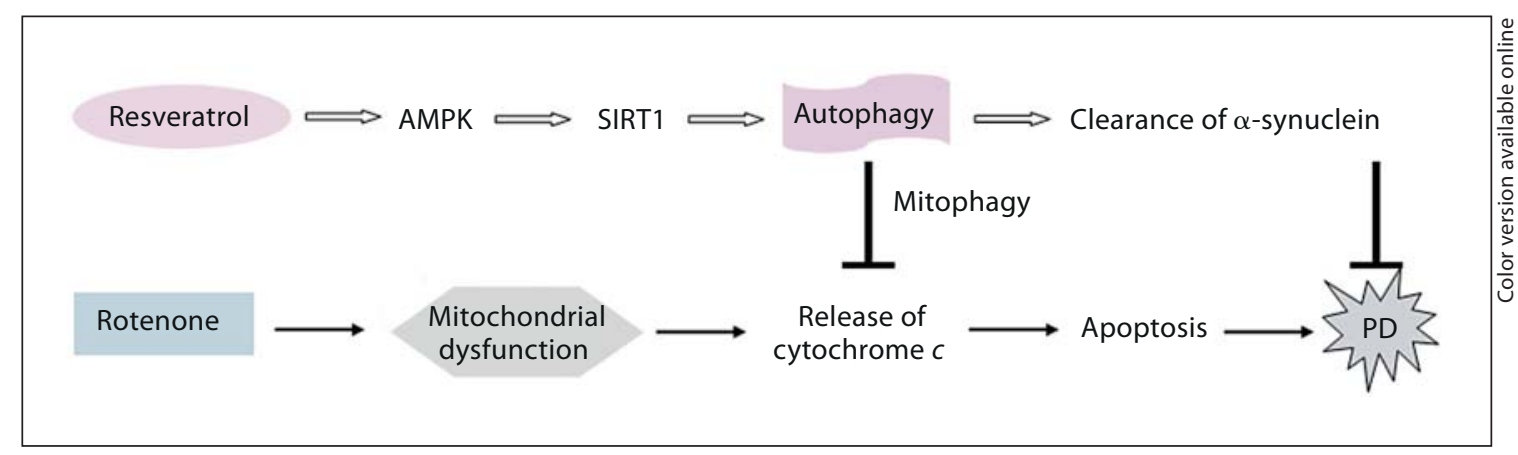

Fig. 7. AMPK/SIRT1/autophagy-mediated neuroprotection by resveratrol. Resveratrol causes activation of AMPK/SIRT1, followed by the induction of autophagy. Induced autophagy enhances the clearance of injured mitochondria, a process termed as ' $m i-$ tophagy', through which the protein level of cytochrome $c$ released from injured mitochondria is decreased, leading to the reduction of rotenone-induced apoptosis. Meanwhile, induced autophagy can enhance the clearance of $\alpha$-synuclein. Both the actions of resveratrol on injured mitochondria and increased $\alpha$-synuclein may contribute to the neuroprotection of resveratrol on PD.

As a nature-derived compound, resveratrol has various biological effects on different species or cell lines and the regulation of autophagy by resveratrol may be through various pathways. Our results showed that suppression of autophagy-related gene Beclin 1 attenuated basal level of LC3 as well as resveratrol-induced increase of LC3-II, indicating that Beclin 1 is involved in the resveratrol-mediated formation of autophagosome. However, as reported previously by Scarlatti et al. [53], autophagy induction by resveratrol was Beclin 1-independent. This discrepant result may come from different cell lines: dopaminergic cells and breast carcinoma cells. It has been reported that Beclin 1 is mutated in $40-70 \%$ of breast and ovarian carcinomas [43] and that MCF-7 breast cancer cells are resistant to apoptotic stimuli due to the lack of caspase-3 [53], all of which are different from SH-SY5Y and PC12 cells.

Activation of AMPK by phosphorylation of $\alpha$ subunit at Thr172 [46] maintains energy balance by switching on a catabolic pathway such as autophagy induction [37]. Consistent with the most recent reports that resveratrol activates AMPK [54-58], we also confirmed that an increased protein level of $\mathrm{p}$-AMPK by resveratrol was accompanied by the increased protein level of LC3-II, an indicator of autophagy induction. However, this effect on autophagy induction was blocked by AMPK inhibitor compound $\mathrm{C}$, indicating that AMPK activation is involved in the induction of autophagy by resveratrol. We also found that inhibition of AMPK attenuated neuroprotective effects of resveratrol on rotenone-induced apoptosis, suggesting that AMPK activation is required in the neuroprotection of resveratrol. In the rotenonetreated SH-SY5Y cellular model of PD, we found that ro- 
tenone could also activate AMPK as indicated by increased protein levels of p-AMPK and p-ACC. However, the results that blockage of AMPK activity by specific AMPK inhibitor enhanced susceptibility of cells to rotenone-induced apoptosis and attenuated neuroprotective roles of resveratrol further supported that activation of AMPK could be a protective effect against the neurotoxic of rotenone and that the neuroprotective effects of resveratrol on rotenone-induced apoptosis could be through AMPK activation. The activation of AMPK by rotenone could be explained by a compensative autoregulation mechanism when the mitochondrial respiratory chain was injured and the supply of ATP was deficient, through which cells provide themselves with energy supplies. But as insults are continuous, cells would fail to continue the autoregulation and lead to cell death, during which time period an exogenous activation of AMPK might be critical for the survival of cells.

Activation of AMPK causes the increase of cellular $\mathrm{NAD}^{+}$levels, which in turn activates $\mathrm{NAD}^{+}$-dependent type III deacetylase sirtuin 1 (SIRT1) activity $[59,60]$, while SIRT1 plays an important role in regulation of pathogenesis of chronic diseases including diabetes, chronic inflammatory pulmonary diseases, neurodegenerative, cardiovascular and chronic renal diseases [61] and in promotion of calorie restriction-mediated longterm survival of mammalian cells [62]. In our study, although resveratrol caused activation of AMPK without being accompanied by a marked increase in SIRT1 protein level, the fact that the protein level of acetylated histone 3 (AC-H3), one of the downstream targets of SIRT1, was decreased in resveratrol-treated cells indicated that deacetylase activity of SIRT1 was increased. Additionally, the result that AMPK inhibitor compound $C$ reversed the resveratrol-induced decrease of $\mathrm{AC}-\mathrm{H} 3$ further suggested the correlation between AMPK and SIRT1. Our results provide evidence that resveratrol may activate the AMPK/SIRT1 pathway, both of which are required for the autophagy induction and for the neuroprotective ef- fects of resveratrol on rotenone-induced apoptosis. Recent publications have also provided with evidence showing that SIRT1 and AMPK-mediated induction of autophagy by resveratrol could be through the mTOR inhibitory pathway $[44,63]$.

It should be noted that a recent report [64] has indicated a contradictive effect of resveratrol on rotenonetreated SH-SY5Y cells. We consider that the discrepancy may result from different time durations of resveratrol treatment. As shown in our results, autophagy was enhanced $24 \mathrm{~h}$ after resveratrol treatment. We consider that $1 \mathrm{~h}$ of incubation with resveratrol [64] may not be enough to induce the autophagy for its neuroprotection through a process called 'mitophagy'.

In conclusion, the neuroprotective effects of resveratrol on PD cellular models are mediated through activation of the AMPK-SIRT1-autophagy pathway (fig. 7). Modulation of the energy metabolic pathway via AMPK or SIRT1 could be a novel neuroprotective strategy for PD.

\section{Acknowledgements}

The authors acknowledge the joint participation by Diana Helis Henry Medical Research Foundation through its direct engagement in the continuous active conduct of medical research in conjunction with Baylor College of Medicine and this program. This work was supported by Carolyn Weiss Law seed funding (2008-2009), National Natural Science Foundation of China (No. 81171205), National Basic Research Program of China (973 Program) (No. 2011CB707506), Shanghai Pujiang Program (11PJD019) and Research Project of Shanghai Municipal Health Bureau (No. 2010106). We also thank Institutional Core Grant \#CA16672 High Resolution Electron Microscopy Facility, UTMDACC, and appreciate the hard work by Kenneth Dunner.

\section{Disclosure Statement}

The authors have no conflicts if interest to disclose.

\section{References}

1 Kopin IJ, Markey SP: MPTP toxicity, implications for research in Parkinson's disease. Annu Rev Neurosci 1988;11:81-96.

- 2 Sherer TB, Betarberbet R, Tasta CM, Seo BB, Richardson JR, Kim JH, Miller GW, Yagi T, Matsuno-Yagi A, Greenamyre JT: Mechanism of toxicity in rotenone models of Parkinson's disease. J Neurosci 2003;23:1075610764.
Bonifati V, Rizzu P, van Baren MJ, Schaap O, Breedveld GJ, Krieger E, Dekker MC, Squitieri F, Ibanez P, Joosse M, van Dongen JW, Vanacore N, van Swieten JC, Brice A, Meco G, van Duijn CM, Oostra BA, Heutink P: Mutations in the DJ-1 gene associated with autosomal recessive early-onset parkinsonism. Science 2003;299:256-259.
4 Valente EM, Abou-Sleiman PM, Caputo V, Muqit MM, Harvey K, Gispert S, Ali Z, Del Turco D, Bentivoglio AR, Healy DG, Albanese A, Nussbaum R, González-Maldonado R, Deller T, Salvi S, Cortelli P, Gilks WP, Latchman DS, Harvey RJ, Dallapiccola B, Auburger G, Wood NW: Hereditary earlyonset Parkinson's disease caused by mutations in PINK1. Science 2004;304:1158-1160. 
5 West AB, Moore DJ, Biskup S, Bugayenko A, Smith WW, Ross CA, Dawson VL, Dawson TM: Parkinson's disease-associated mutations in leucine-rich repeat kinase 2 augment kinase activity. Proc Natl Acad Sci USA 2005; 102:16842-16847.

6 Rubinsztein DC: The roles of intracellular protein-degradation pathways in neurodegeneration. Nature 2006;443:780-786.

7 Pan T, Rawal P, Wu Y, Xie W, Jankovic J, Le $\mathrm{W}$ : Rapamycin protects against rotenone-induced apoptosis through autophagy induction. Neuroscience 2009;164:541-551.

8 Irrcher I, Park DS: Parkinson's disease, to live or die by autophagy. Sci Signal 2009; 2:pe21.

-9 Pan T, Kondo S, Le W, Jankovic J: The role of autophagy-lysosome pathway in neurodegeneration associated with Parkinson's disease. Brain 2008;131:1969-1978.

- 10 Elmore SP, Qian T, Grissom SF, Lemasters JJ: The mitochondrial permeability transition initiates autophagy in rat hepatocytes. FASEB J 2001;15:2286-2287.

$\checkmark 11$ Levine B: Eating oneself and uninvited guests, autophagy-related pathways in cellular defense. Cell 2005;120:159-162.

-12 Lum JJ, Bauer DE, Kong M, Harris MH, Li C, Lindsten T, Thompson CB: Growth factor regulation of autophagy and cell survival in the absence of apoptosis. Cell 2005;120:237248.

13 Li X, Lu Y, Pan T, Fan Z: Roles of autophagy in cetuximab-mediated cancer therapy against EGFR. Autophagy 2010;6:10661077.

-14 Komatsu M, Waguri S, Chiba T, Murata S, Iwata J, Tanida I, Ueno T, Koike M, Uchiyama Y, Kominami E, Tanaka K: Loss of autophagy in the central nervous system causes neurodegeneration in mice. Nature 2006; 441:880-884.

15 Williams A, Jahreiss L, Sarkar S, Saiki S, Menzies FM, Ravikumar B, Rubinsztein DC: Aggregate-prone proteins are cleared from the cytosol by autophagy, therapeutic implications. Curr Top Dev Biol 2006;76:89-101.

$\checkmark 16$ Gorman AM: Neuronal cell death in neurodegenerative diseases, recurring themes around protein handling. J Cell Mol Med 2008;12:2263-2280.

$\checkmark 17$ Cheung ZH, Ip NY: The emerging role of autophagy in Parkinson's disease. Mol Brain 2009;2:29.

-18 Mizushima N, Levine B, Cuervo AM, Klionsky DJ: Autophagy fights disease through cellular self-digestion. Nature 2008;451: 1069-1075.

19 McCray BA, Taylor JP: The role of autophagy in age-related neurodegeneration. Neurosignals 2008; 16:75-84.

20 Pervaiz S, Holme AL: Resveratrol: its biologic targets and functional activity. Antioxid Redox Signal 2009;11:2851-2897.
21 Albani D, Polito L, Batelli S, De Mauro S, Fracasso C, Martelli G, Colombo L, Manzoni C, Salmona M, Caccia S, Negro A, Forloni G: The SIRT1 activator resveratrol protects SK-N-BE cells from oxidative stress and against toxicity caused by $\alpha$-synuclein or amyloid- $\beta$ (1-42) peptide. J Neurochem 2009;110:1445-1456.

22 Haigis MC, Guarente LP: Mammalian sirtuins - emerging roles in physiology, aging, and calorie restriction. Genes Dev 2006;20: 2913-2921.

23 Michan S, Sinclair D: Sirtuins in mammals: insights into their biological function. Biochem J 2007;404:1-13.

24 Hsieh TC, Wu JM: Resveratrol: biological and pharmaceutical properties as anticancer molecule. Biofactors 2010;36:360-369.

25 Huang C, Ma WY, Goranson A, Dong Z: Resveratrol suppresses cell transformation and induces apoptosis through a p53-dependent pathway. Carcinogenesis 1999;20:237242.

26 Doré S: Unique properties of polyphenol stilbenes in the brain: more than direct antioxidant actions; gene/protein regulatory activity. Neurosignals 2005;14:61-70.

27 De la Lastra CA, Villegas I: Resveratrol as an anti-inflammatory and anti-aging agent, mechanisms and clinical implications. Mol Nutr Food Res 2005;49:405-430.

28 Shakibaei M, Harikumar KB, Aggarwal BB: Resveratrol addiction, to die or not to die. Mol Nutr Food Res 2009;53:115-128.

29 Zhang Z, Lowry SF, Guarente L, Haimovich B: Roles of Sirt1 in the acute and restorative phases following induction of inflammation. J Biol Chem 2010;285:41391-41401.

30 Lee MK, Kang SJ, Poncz M, Song KJ, Park KS: Resveratrol protects SH-SY5Y neuroblastoma cells from apoptosis induced by dopamine. Exp Mol Med 2007;39:376-384.

31 Jin F, Wu Q, Lu YF, Gong QH, Shi JS: Neuroprotective effect of resveratrol on 6-OHDAinduced Parkinson's disease in rats. Eur J Pharmacol 2008;600:78-82.

- 32 Blanchet J, Longpré F, Bureau G, Morissette M, DiPaolo T, Bronchti G, Martinoli MG: Resveratrol, a red wine polyphenol, protects dopaminergic neurons in MPTP-treated mice. Prog Neuropsychopharmacol Biol Psychiatry 2008;32:1243-1250.

$33 \mathrm{Lu}$ KT, Ko MC, Chen BY, Huang JC, Hsieh CW, Lee MC, Chiou RY, Wung BS, Peng CH, Yang YL: Neuroprotective effects of resveratrol on MPTP-induced neuron loss mediated by free radical scavenging. J Agric Food Chem 2008;56:6910-6913.

34 Pallàs M, Casadesús G, Smith MA, CotoMontes A, Pelegri C, Vilaplana J, Camins A: Resveratrol and neurodegenerative diseases: activation of SIRT1 as the potential pathway towards neuroprotection. Curr Neurovasc Res 2009;6:70-81.
35 Lee IH, Cao L, Mostoslavsky R, Lombard DB, Liu J, Bruns NE, Tsokos M, Alt FW, Finkel T: A role for the NAD-dependent deacetylase Sirt1 in the regulation of autophagy. Proc Natl Acad Sci USA 2008; 105:3374-3379.

- 36 Poels J, Spasić MR, Callaerts P, Norga KK: Expanding roles for AMP-activated protein kinase in neuronal survival and autophagy. Bioessays 2009;31:944-952.

37 Hardie DG: AMP-activated/SNF1 protein kinases, conserved guardians of cellular energy. Nat Rev Mol Cell Biol 2007;8:774-785.

38 Vingtdeux V, Chandakkar P, Zhao $\mathrm{H}$, d'Abramo C, Davies P, Marambaud P: Novel synthetic small-molecule activators of AMPK as enhancers of autophagy and amyloid- $\beta$ peptide degradation. FASEB J 2011;25:219231.

39 Sarkar S, Davies JE, Huang Z, Tunnacliffe A, Rubinsztein DC: Trehalose, a novel mTORindependent autophagy enhancer, accelerates the clearance of mutant huntingtin and $\alpha$-synuclein. J Biol Chem 2007;282:56415652.

40 Sarkar S, Ravikumar B, Rubinsztein DC: Autophagic clearance of aggregate-prone proteins associated with neurodegeneration. Methods Enzymol 2009;453:83-110.

41 Wu Y, Li X, Xie W, Jankovic J, Le W, Pan T: Neuroprotection of deferoxamine on rotenone-induced injury via accumulation of HIF- $1 \alpha$ and induction of autophagy in SHSY5Y cells. Neurochem Int 2010;57:198-205.

-42 Pan T, Kondo S, Zhu W, Xie W, Jankovic J, Le W: Neuroprotection of rapamycin in lactacystin-induced neurodegeneration via autophagy enhancement. Neurobiol Dis 2008; 32:16-25.

43 Corcelle EA, Puustinen P, Jäättelä M: Apoptosis and autophagy: targeting autophagy signalling in cancer cells - 'trick or treats'? FEBS J 2009;276:6084-6096.

44 Puissant A, Robert G, Fenouille N, Luciano F, Cassuto JP, Raynaud S, Auberger P: Resveratrol promotes autophagic cell death in chronic myelogenous leukemia cells via JNK-mediated p62/SQSTM1 expression and AMPK activation. Cancer Res 2010;70:10421052.

45 Yamamoto A, Tagawa Y, Yoshimori T, Moriyama Y, Masaki R, Tashiro Y: Bafilomycin Al prevents maturation of autophagic vacuoles by inhibiting fusion between autophagosomes and lysosomes in rat hepatoma cell line, H-4-II-E cells. Cell Struct Funct 1998;23:33-42.

-46 Hawley SA, Davison M, Woods A, Davies SP, Beri RK, Carling D, Hardie DG: Characterization of the AMP-activated protein kinase kinase from rat liver and identification of threonine-172 as the major site at which it phosphorylates AMP-activated protein kinase. J Biol Chem 1996;271:27879-27887.

47 Hardie DG, Carling D, Carlson M: The AMP-activated/SNF1 protein kinase subfamily, metabolic sensors of the eukaryotic cell? Annu Rev Biochem 1998;67:821-855. 
-48 Lee M, Hwang JT, Lee HJ, Jung SN, Kang I, Chi SG, Kim SS, Ha J: AMP-activated protein kinase activity is critical for hypoxia-inducible factor- 1 transcriptional activity and its target gene expression under hypoxic conditions in DU145 cells. J Biol Chem 2003; 278:39653-29661.

49 Jung SN, Yang WK, Kim J, Kim HS, Kim EJ, Yun H, Park H, Kim SS, Choe W, Kang I, Ha J: Reactive oxygen species stabilize hypoxiainducible factor- $1 \alpha$ protein and stimulate transcriptional activity via AMP-activated protein kinase in DU145 human prostate cancer cells. Carcinogenesis 2008;29:713721.

50 Mizushima N: Autophagy, process and function. Genes Dev 2007;21:2861-2873.

-51 Cuervo AM, Stefanis L, Fredenburg R, Lansbury PT, Sulzer D: Impaired degradation of mutant $\alpha$-synuclein by chaperone-mediated autophagy. Science 2004;305:1292-1295.

-52 Webb JL, Ravikumar B, Atkins J, Skepper JN, Rubinsztein DC: Alpha-synuclein is degraded by both autophagy and the proteasome. J Biol Chem 2003;278:25009-25013.

- 53 Scarlatti F, Maffei R, Beau I, Codogno P, Ghidoni R: Role of non-canonical Beclin 1-independent autophagy in cell death induced by resveratrol in human breast cancer cells. Cell Death Differ 2008;15:1318-1329.
4 Baur JA, Pearson KJ, Price NL, Jamieson HA, Lerin C, Kalra A, Prabhu VV, Allard JS, Lopez-Lluch G, Lewis K, Pistell PJ, Poosala S, Becker KG, Boss O, Gwinn D, Wang M, Ramaswamy S, Fishbein KW, Spencer RG, Lakatta EG, Le Couteur D, Shaw RJ, Navas P, Puigserver P, Ingram DK, de Cabo R, Sinclair DA: Resveratrol improves health and survival of mice on a high-calorie diet. Nature 2006;444:337-342.

55 Dasgupta B, Milbrandt J: Resveratrol stimulates AMP kinase activity in neurons. Proc Natl Acad Sci USA 2007;104:7217-7222.

56 Park CE, Kim MJ, Lee JH, Min BI, Bae H, Choe W, Kim SS, Ha J: Resveratrol stimulates glucose transport in $\mathrm{C} 2 \mathrm{C} 12$ myotubes by activating AMP-activated protein kinase. Exp Mol Med 2007;39:222-229.

57 Wang A, Liu M, Liu X, Dong LQ, Glickman RD, Slaga TJ, Zhou Z, Liu F: Up-regulation of adiponectin by resveratrol: the essential roles of the Akt/FOXO1 and AMPK signaling pathways and DsbA-L. J Biol Chem 2011; 286:60-66.

58 Kwon KJ, Kim HJ, Shin CY, Han SH: Melatonin potentiates the neuroprotective properties of resveratrol against $\beta$-amyloid-induced neurodegeneration by modulating AMP-activated protein kinase pathways. J Clin Neurol 2010;6:127-137.
9 Cantó C, Gerhart-Hines Z, Feige JN, Lagouge M, Noriega L, Milne JC, Elliott PJ, Puigserver P, Auwerx J: AMPK regulates energy expenditure by modulating $\mathrm{NAD}^{+}$metabolism and SIRT1 activity. Nature 2009; 458:1056-1060.

60 Chau MD, Gao J, Yang Q, Wu Z, Gromada J: Fibroblast growth factor-21 regulates energy metabolism by activating the AMPK-SIRT1PGC- $1 \alpha$ pathway. Proc Natl Acad Sci USA 2010;107:12553-12558.

61 Chung S, Yao H, Caito S, Hwang JW, Arunachalam G, Rahman I: Regulation of SIRT1 in cellular functions, role of polyphenols. Arch Biochem Biophys 2010;501:79-90.

62 Cohen HY, Miller C, Bitterman KJ, Wall NR, Hekking B, Kessler B, Howitz KT, Gorospe M, de Cabo R, Sinclair DA: Calorie restriction promotes mammalian cell survival by inducing the SIRT1 deacetylase. Science 2004;305:390-392.

63 Ghosh HS, McBurney M, Robbins PD: SIRT1 negatively regulates the mammalian target of rapamycin. PLoS One 2010;5:e9199.

64 Filomeni G, Graziani I, De Zio D, Dini L, Centonze D, Rotilio G, Ciriolo MR: Neuroprotection of kaempferol by autophagy in models of rotenone-mediated acute toxicity, possible implications for Parkinson's disease. Neurobiol Aging 2010 (doi 10.1016/j. neurobiolaging.2010.05.021). 